Research Article

\title{
Adoption of a Patient-Tailored Fall Prevention Program in Academic Health Systems: A Qualitative Study of Barriers and Facilitators
}

Eileen J. Carter ${ }^{1,}{ }^{*}$, Srijesa Khasnabish ${ }^{2}$, Jason S. Adelman ${ }^{3}$, Michael Bogaisky ${ }^{4}$, Mary Ellen Lindros ${ }^{5}$, Lois Alfieri ${ }^{5}$, Maureen Scanlan ${ }^{5}$, Ann Hurley ${ }^{2}$, Megan Duckworth ${ }^{2}$, Alexandra Shelley ${ }^{6}$, Kenrick Cato ${ }^{1,3}$, Shao P Yu ${ }^{3}$, Dianne L Carroll ${ }^{7}$, Emily Jackson ${ }^{3}$, Stuart Lipsitz ${ }^{8}$, David W Bates ${ }^{8}$, Patricia C. Dykes $^{8}$

1. Columbia University School of Nursing, New York, NY, USA; E-Mail: em2473@columbia.edu

2. Brigham and Women's Hospital, Boston, MA, USA; E-Mails: skhasnabish@bwh.harvard.edu; AHURLEY@PARTNERS.ORG; megan duckworth@brown.edu

3. NewYork-Presbyterian Hospital/Columbia University Irving Medical Center, New York, NY, USA; E-Mails: jsa2163@cumc.columbia.edu; kec7005@nyp.org; shy7002@nyp.org; emj9009@nyp.org

4. Albert Einstein College of Medicine Montefiore Medical Center, New York, NY, USA; E-Mail: MBOGAISK@montefiore.org

5. Montefiore Medical Center, Bronx, NY, USA; E-Mails: mlindros@montefiore.org; LALFIERI@montefiore.org; MSCANLAN@montefiore.org

6. NewYork-Presbyterian/Lower Manhattan Hospital, New York, NY, USA; E-Mail: ajn9002@nyp.org

7. Yvonne L. Munn Center for Nursing Research, Massachusetts General Hospital, Boston, MA, USA; E-Mail: DCARROLL3@mgh.harvard.edu

8. Brigham and Women's Hospital, Harvard Medical School, Boston, MA, USA; E-Mails: slipsitz@bwh.harvard.edu; dbates@bwh.harvard.edu; PDYKES@BWH.HARVARD.EDU

* Correspondence: Eileen J. Carter; E-Mail: em2473@columbia.edu

Academic Editors: James S. Powers and Lisa A. Hollis-Sawyer

OBM Geriatrics

2020, volume 4, issue 2

doi:10.21926/obm.geriatr.2002119
Received: March 23, 2020

Accepted: May 07, 2020

Published: May 18, 2020

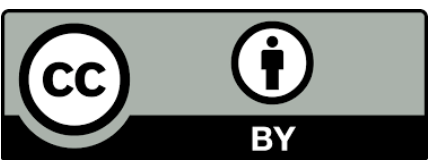

(C) 2020 by the author. This is an open access article distributed under the conditions of the Creative Commons by Attribution License, which permits unrestricted use, distribution, and reproduction in any medium or format, provided the original work is correctly cited. 


\begin{abstract}
Falls represent a persistent and costly patient safety issue. Fall TIPS (Tailored Interventions for Patient Safety) is a patient-centered and clinical decision-supported, fall prevention program that has led to fewer falls and related injuries among hospitalized patients. We aimed to identify dominant facilitators and barriers to Fall TIPS adoption. This multisite qualitative study was conducted in 11 hospitals representing three academic health systems, where Fall TIPS had been implemented for at least one year. Interviews with 50 patients and focus groups with 71 staff were analyzed using a conventional content analysis. Fall TIPS resulted in a partnership between staff and patients, in which fall prevention interventions were patient-specific and enabled by clinical decision support. We identified three facilitators to program adoption. First, staff were motivated to address falls as staff recognized fall prevention as a priority and the limitations of previous fall prevention programs. Second, patients welcomed their role in fall prevention. Third, Fall TIPS was integrated into existing staff workflows. We identified three dominant barriers to program adoption. First, poor engagement practices among staff limited patients' active participation in fall prevention. Second, the use of residual fall prevention approaches perpetuated a 'one-size fits all' approach to fall prevention. Third, patient willfulness i.e., patients' conscious deviation from fall plans challenged program fidelity. Fall TIPS changed the paradigm of fall prevention by placing an unprecedented focus on patient engagement. Actions that improve staffs' engagement of patients and patient's partnership in fall prevention will assist Fall TIPS adoption.
\end{abstract}

\title{
Keywords
}

Falls; patient-engagement; qualitative

\section{Introduction}

Falls in acute care hospitals represent a persistent patient safety issue. Approximately 3-4 falls occur per 1,000 patient days [1, 2] and nearly $25 \%$ of patients who fall sustain an injury [2]. Injurious falls are costly, adding over 6 days to a patient's hospitalization [3]. Due to their preventable nature, falls are no longer reimbursed by the Centers for Medicare and Medicaid Services [4]. Meta-analyses suggest that $30 \%$ of patient falls are avoidable [5]. Yet, because the exact components of a fall prevention bundle are not established, fall prevention programs traditionally rely on staff to select interventions they perceive will address a patient's fall risks [6] or universal fall precautions, which involve implementation of the same set of interventions on all patients [5].

To our knowledge, Fall TIPS (Tailoring Interventions for Patient Safety) was the first patientcentered and clinical decision-supported fall prevention program tested in a randomized controlled trial [7]. Since the original study found that Fall TIPS significantly reduced in-hospital falls by $25 \%$ [7] and subsequent studies show decreases in fall injury rates post-Fall TIPS implementation [8], 126 hospitals in the U.S. have adopted the program [9]. Fall TIPS is characterized by nurses' active engagement of patients and their families in three-steps of fall 
prevention: 1) identifying a patient's risk for falls using a valid and reliable screening scale; 2 ) using clinical decision support to develop a tailored fall prevention plan that links falling risks with evidence informed interventions [10] as well as displaying the patient's fall prevention plan at the patient's bedside for all stakeholders to see; and 3) implementing the fall prevention plan consistently. Fall TIPS prevention plans come in two formats; a printed poster that is autopopulated with electronic health record data [7] (Figure 1A) or a laminated poster that staff complete [8] (Figure 1B). Both are posted at the patient's bedside. Although the evidenced-based Fall TIPS program is rapidly spreading across U.S. hospitals, little is known about what leads to or impedes a successful Fall TIPS program implementation. To answer this question, we performed a multisite qualitative study to assess the dominant barriers and facilitators to the adoption of Fall TIPS.

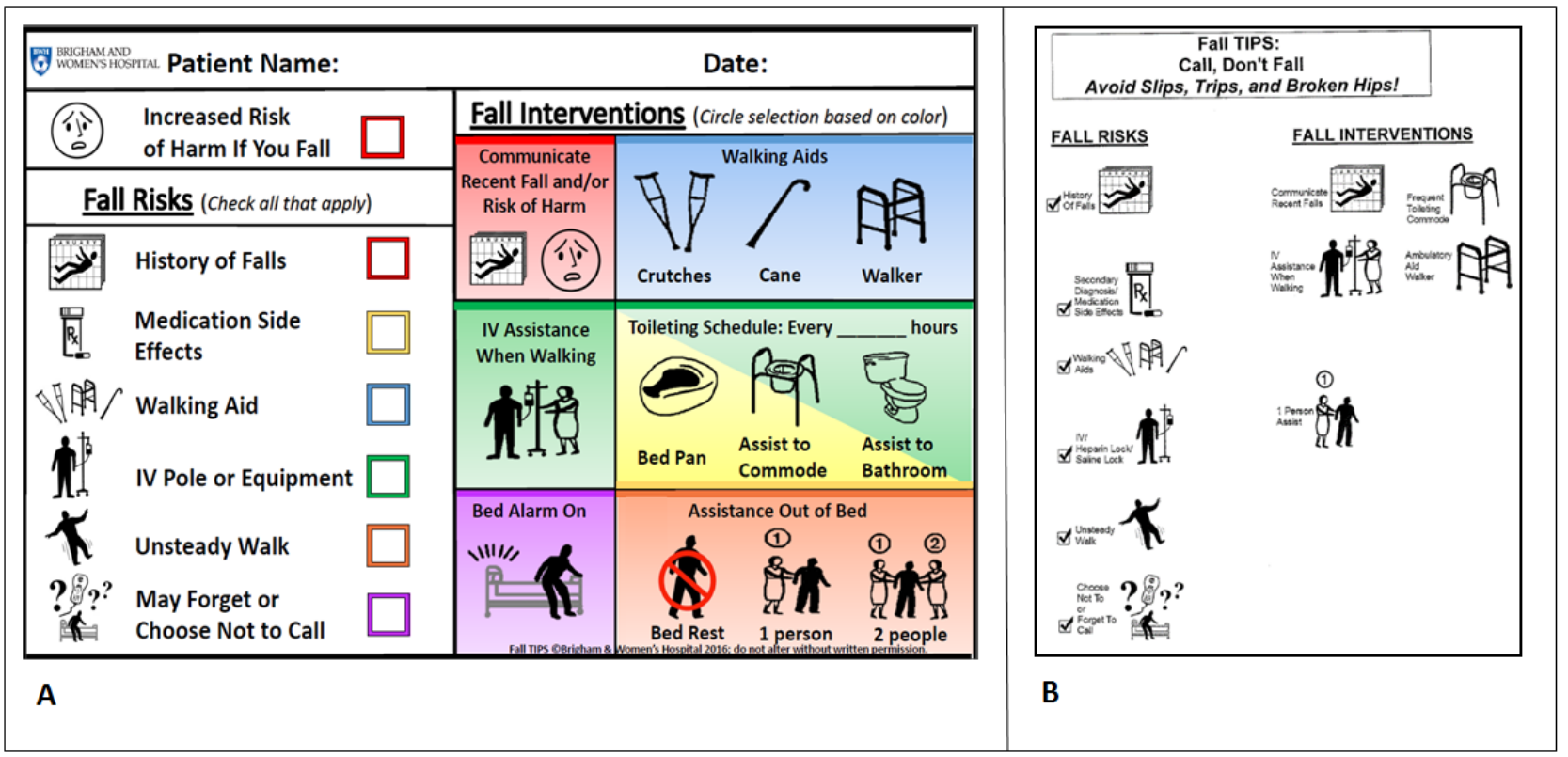

Figure 1 Fall TIPS fall prevention plans. A: Laminated paper Fall TIPS bedside poster, on which the nurse manually documents the patient's fall risks and tailored intervention plan. B: Electronic Fall TIPS bedside poster, generated by nurse documentation in the electronic health record.

\section{Methods}

\subsection{Design and Study Setting}

This was a multisite qualitative study. Participants were recruited from eleven hospitals that were part of three academic health systems where Fall TIPS had been successfully implemented for at least one year. We define successful implementation as hospitals with audit data indicating a minimum of $80 \%$ Fall TIPS program compliance for $\geq 6$ months [8]. We selected these criteria as program compliance is associated with decreased falls [8] and because we were interested in program sustainability. We conducted semi-structured interviews and focus groups with key stakeholders (i.e. patients and staff) on general oncology, medical, surgical, or combined medicalsurgical units where Fall TIPS had been implemented. Individual interviews with patients and their 
families (if available), lasted 15-60 minutes and focus groups, ranging from 3-10 participants with staff, lasted 30-60 minutes. Individual interviews ensured the confidentiality of patient information, whereas staff focus groups facilitated group exchange and dialogue. The institutional review boards of participating health systems approved this study with a waiver of documentation of informed consent.

\subsection{Participants and Recruitment}

Participants were sampled based on their exposure to Fall TIPS. Specifically, staff who provided care and patients who received care on units where Fall TIPS was implemented were targeted for recruitment. To facilitate the ease of scheduling, focus groups were held in conjunction with preexisting staff meetings. Patients were eligible to participate if they were alert and oriented and were English speaking or had an English-speaking family member to facilitate. Eligible patients were identified by members of their healthcare team and had no direct relationship with study investigators.

\subsection{Interview Guide}

Semi-structured interview guides were used to facilitate data collection. Separate guides were used for patients (Supplement A) and for staff (Supplement B) to account for their unique experiences and perspectives. Interview guides were based on a review of the fall prevention literature, the RE-AIM framework [10] (reach, effectiveness, adoption, implementation, and maintenance) and iteratively refined over the course of data collection to account for emergent findings.

\subsection{Data Collection and Analysis}

Staff focus groups and patient interviews were conducted in two phases. In Phase 1, (July September 2017), dominant barriers and facilitators to Fall TIPS were identified. Phase 1 continued until saturation was reached, e.g., newly collected data were confirmatory, offering little insight. In Phase 2, (May - June 2018), Phase 1 findings were discussed with key stakeholders to examine their accuracy. Phase 2 continued until findings from Phase 1 were validated or rejected. Two to three investigators conducted interviews and focus groups at each study hospital. These investigators attended a full-day continuing education approved workshop, led by two qualitative research experts $(A H$ and $P C D)$, where they received training in qualitative data collection and demonstrated competency in interviewing techniques.

Upon verbal consent from participants, interviews were audio-recorded and data were transcribed verbatim using an automated transcription service, Trint (2018). To ensure transcription accuracy, transcripts were reviewed by both the study coordinator and investigator who conducted the interview/focus group. Four investigators ( $A H, P C D, S K, M D)$ analyzed transcripts using conventional content analysis [11], in which codes were identified a priori (based on a review of falls literature and the RE-AIM framework) and emerged from transcript data. Coding was performed in NVivo (QSR International 2002) using a consensus approach in which researchers collectively identified codes, applied codes, and discussed discrepancies to gain agreement. To ensure the validity of qualitative findings [12], researchers engaged in 1) bi-weekly 
peer debriefings, in which transcript data were shared with researchers not part of the qualitative investigation to solicit objective perspectives of findings; and 2) member checking, in which interim qualitative findings were discussed with patients and staff to confirm their accuracy (i.e., Phase 2).

\section{Results}

A total of 71 staff participated in 11 focus groups and 50 patients and 7 family members participated in individual interviews across study phases, Table 1. Among staff participants, mean age was 38.6 (SD 1.6); most were nurses (93.8\%), female (90.1\%), white (35.2\%), and had received a bachelor's degree or higher (94.3\%), Table 2 . Among patient participants, most were female $(60.0 \%)$, white $(44.0 \%)$ and $40 \%$ of participants were 65 years of age or older. At the time of patient interviews, patients had a mean length of stay 7.9 days.

Table 1 Study participants by site and phase.

\begin{tabular}{|l|c|c|c|c|c|c|c|}
\hline & \multicolumn{2}{|c|}{$\begin{array}{c}\text { Health System 1 } \\
\text { (Hospitals A, B, C, and } \\
\text { D) }\end{array}$} & \multicolumn{2}{|c|}{$\begin{array}{c}\text { Health System 3 } \\
\text { Health System 2 } \\
\text { (Hospitals E, F, and G) }\end{array}$} & $\begin{array}{c}\text { Keaspitals H, I, J and } \\
\text { (H) C }\end{array}$ & $\begin{array}{l}\text { TOTAL } \\
\text { (N) }\end{array}$ \\
\hline & Phase 1 & Phase 2 & Phase 1 & Phase 2 & Phase 1 & Phase 2 & \\
\hline $\begin{array}{l}\text { Staff } \\
\text { Participants } \\
\text { (N) }\end{array}$ & 10 & 8 & 22 & 6 & 20 & 5 & $\mathbf{7 1}$ \\
\hline Patients (N) & 9 & 8 & 13 & 6 & 8 & 6 & $\mathbf{5 0}$ \\
\hline $\begin{array}{l}\text { Patient } \\
\text { Family (N) }\end{array}$ & 2 & 2 & 2 & 0 & 1 & 0 & $\mathbf{7}$ \\
\hline
\end{tabular}


Table 2 Participant demographics.

\begin{tabular}{|c|c|c|}
\hline & $\begin{array}{l}\text { Staff Participants } \\
\mathrm{N}=71\end{array}$ & $\begin{array}{l}\text { Patient Participants } \\
\mathrm{N}=50\end{array}$ \\
\hline Age in years, mean (SD); No. (\%) & $38.6(1.6)$ & $\begin{array}{l}\text { Below 65: } 30(60.0) \\
\text { Between } 65 \text { and 75: } 15(30.0) \\
\text { Above 75: } 5 \text { (10.0) }\end{array}$ \\
\hline Female sex, No. (\%) & $64(90.1)$ & $30(60.0)$ \\
\hline \multicolumn{3}{|l|}{ Ethnic Group, No. (\%) } \\
\hline Hispanic & $6(8.4)$ & $12(24.0)$ \\
\hline Non-Hispanic & $58(81.7)$ & $38(76.0)$ \\
\hline Not reporting & $7(9.9)$ & $0(0)$ \\
\hline \multicolumn{3}{|l|}{ Race, No. (\%) } \\
\hline American Indian/Alaskan Native & $0(0)$ & $0(0)$ \\
\hline Asian & $13(18.3)$ & $0(0)$ \\
\hline Native Hawaiian & $0(0)$ & $1(2.0)$ \\
\hline Black or African American & $23(32.4)$ & $17(34.0)$ \\
\hline White & $25(35.2)$ & $22(44.0)$ \\
\hline More than One Race & $5(7.0)$ & $\mathrm{N} / \mathrm{A}$ \\
\hline Not Reporting & $5(7.0)$ & $2(4.0)$ \\
\hline Other & N/A & $8(16.0)$ \\
\hline \multicolumn{3}{|l|}{ Highest Professional Degree, No. (\%) } \\
\hline Diploma & $3(4.2)$ & $\mathrm{N} / \mathrm{A}$ \\
\hline$A D$ & $1(1.4)$ & $\mathrm{N} / \mathrm{A}$ \\
\hline $\mathrm{BS} / \mathrm{BA}$ & $50(70.4)$ & $\mathrm{N} / \mathrm{A}$ \\
\hline $\mathrm{MA} / \mathrm{MS}$ & $16(22.5)$ & $\mathrm{N} / \mathrm{A}$ \\
\hline $\begin{array}{l}\text { Doctoral Degree (MD, DPT, } \\
\text { PharmD, OTD, PhD) }\end{array}$ & $1(1.4)$ & $\mathrm{N} / \mathrm{A}$ \\
\hline
\end{tabular}

We found that Fall TIPS facilitated a paradigm shift in fall prevention. Pre-Fall TIPS, staff described that fall prevention was staff-driven and patient involvement was scant. Staff would use their hospital's fall risk screening assessment to identify patients at "high" and "low" falls risk and would accordingly implement "high" or "low" fall prevention interventions on patients. Patients at high-falls risk were commonly noted to receive a colorful item to don (e.g., wristband, socks), a generic high-falls risk sign posted at their bedside, and bed alarms that would sound when attempting to leave bed. For patients considered very high-falls risk, additional interventions were implemented at staffs' discretion (e.g., 1:1 sitter, placement of patients in close proximity to nurses' station, etc.). Post-Fall TIPS, staff described their engagement of patients and family in the identification of fall-risk factors and implementation of fall plans, as well as the use of clinical decision support to identify interventions that addressed individual fall risks. Content analysis revealed primary and secondary facilitators and barriers to Fall TIPS adoption. Facilitators and barriers are described below and depicted using representative quotes in Table 3 and Table 4, respectively. 
Table 3 Dominant facilitators to fall TIPS adoption.

\begin{tabular}{|c|c|}
\hline Theme & Representative Quote \\
\hline \multicolumn{2}{|c|}{ Frontline staff were motivated to address falls } \\
\hline $\begin{array}{l}\text { Falls became a standing } \\
\text { agenda item during daily } \\
\text { huddles and staff meetings }\end{array}$ & $\begin{array}{l}\text { "On my unit every morning ... we huddle then we do a team } \\
\text { around... we make sure we're checking the boards to make sure the } \\
\text { right person's name there, make sure they have a TIPS poster and } \\
\text { consistently we do that every morning to make sure everyone has a } \\
\text { TIPS poster." Nurse -Hospital E }\end{array}$ \\
\hline $\begin{array}{l}\text { Nurses received mandatory } \\
\text { Fall TIPS trainings }\end{array}$ & $\begin{array}{l}\text { "II] remember we had that fall prevention week and we did the kick } \\
\text { off...The education that was provided with Fall TIPS was key to the } \\
\text { success of Fall TIPS because people who are able to understand what } \\
\text { each section in the Morse Fall Scale was" - Nurse, Hospital A }\end{array}$ \\
\hline $\begin{array}{l}\text { Nurses routinely received } \\
\text { falls process and outcomes } \\
\text { data }\end{array}$ & $\begin{array}{l}\text { "Now that we have the boards every unit has that board that we } \\
\text { have the fall, the QI board one with the green dots and the yellow } \\
\text { dots, fall with injury fall with no injury, no fall. So every day we look } \\
\text { forward to it." - Nurse, Hospital F }\end{array}$ \\
\hline $\begin{array}{l}\text { Nurses recognized the } \\
\text { limitations of their previous } \\
\text { fall prevention program }\end{array}$ & $\begin{array}{l}\text { "[Pre Fall-TIPS we] did our signs, put in the plan of care, yellow dot } \\
\text { and that's it. Cross your fingers... Hope they don't fall." - Nurse, } \\
\text { Hospital A }\end{array}$ \\
\hline \multicolumn{2}{|c|}{ Patients and their families welcomed their role in falls prevention } \\
\hline $\begin{array}{l}\text { Nurses initiated } \\
\text { conversations regarding fall } \\
\text { risks and interventions }\end{array}$ & $\begin{array}{l}\text { "I was very cognizant of fall prevention because they [nurses] made } \\
\text { me aware of it" - Patient, Hospital I }\end{array}$ \\
\hline $\begin{array}{l}\text { Patients readily understood } \\
\text { the need for individualized } \\
\text { fall plans }\end{array}$ & $\begin{array}{l}\text { "I like that every patient has their own prescription. So what may be } \\
\text { a fall risk for me wouldn't be a fall risk for the young lady across the } \\
\text { hall or hers can be a lot slimmer to none than mine or mine can be } \\
\text { slimmer than hers. So I think it's very, very, useful."- Patient, Hospital } \\
\text { G }\end{array}$ \\
\hline $\begin{array}{l}\text { Bedside posters of individual } \\
\text { fall plans facilitated patient } \\
\text { and family engagement in } \\
\text { falls }\end{array}$ & $\begin{array}{l}\text { "TIPS is very helpful and visual because it does get a lot of patient } \\
\text { and family involvement... With the TIPS posters, it's more of an } \\
\text { interactive conversation regarding falls." - Nurse, Hospital G }\end{array}$ \\
\hline \multicolumn{2}{|c|}{ Fall TIPS was integrated into existing staff workflows } \\
\hline $\begin{array}{l}\text { Clinical decision support } \\
\text { aided nurses' in identifying } \\
\text { interventions to address } \\
\text { patient's individualized risks } \\
\text { for falls }\end{array}$ & $\begin{array}{l}\text { "As soon as you check that off, it drives you, it forces you, 'ok, and } \\
\text { this patient needs toileting schedule.' In other words, because this } \\
\text { patient has an IV access, what is appropriate for the patient?" - } \\
\text { Nurse, Hospital H }\end{array}$ \\
\hline $\begin{array}{l}\text { Fall TIPS was integrated into } \\
\text { existing staff workflows }\end{array}$ & $\begin{array}{l}\text { "[It] just goes into the flow, we were already doing our flow sheet, } \\
\text { we do our flow sheets and... we make sure we print our tips posters } \\
\text { when the patient comes onto the floor." - Nurse, Hospital E }\end{array}$ \\
\hline
\end{tabular}


Table 4 Dominant barriers to Fall TIPS adoption.

\begin{tabular}{|c|c|}
\hline Theme & Representative Quote \\
\hline \multicolumn{2}{|c|}{ Poor engagement practices among staff } \\
\hline $\begin{array}{l}\text { Patients were educated, } \\
\text { rather than engaged in falls } \\
\text { prevention }\end{array}$ & $\begin{array}{l}\text { "Just print it [bedside fall plan poster] out after you do your } \\
\text { assessment. Usually we explain why we're putting this poster up to } \\
\text { the patient. It's a safety intervention to help prevent falls. These } \\
\text { are the reasons why you're a fall risk." - Nurse, Hospital E }\end{array}$ \\
\hline $\begin{array}{l}\text { Inaccurate falls-risk } \\
\text { assessments and associated } \\
\text { bedside posters }\end{array}$ & $\begin{array}{l}\text { "I wouldn't want to } 100 \% \text { trust that every time because it } \\
\text { probably... wasn't updated that day honestly." - Nurse, Hospital C } \\
\text { "I think a barrier would be when it's not updated...Another issue is } \\
\text { at discharge we're supposed to be taking them down. And } \\
\text { sometimes it's just so busy and you forget to." - Nurse, Hospital K }\end{array}$ \\
\hline \multicolumn{2}{|c|}{ Residual language and fall prevention approaches } \\
\hline $\begin{array}{l}\text { "High" and "low" falls-risk } \\
\text { categories and } \\
\text { accompanying interventions } \\
\text { persisted from previous fall } \\
\text { prevention programs }\end{array}$ & $\begin{array}{l}\text { "There are tags that we would put outside the patient's door, that } \\
\text { this patient is high or this patient is low. It's on the chart there is a } \\
\text { checklist and you just check that off." - Nurse, Hospital H } \\
\text { "During huddles we identify the patients who are at risk for fall and } \\
\text { who has the bed alarm on and what zone it's in... We have } \\
\text { interventions if the patient is at high risk for falls." - Nurse, } \\
\text { Hospital F }\end{array}$ \\
\hline Patient willfulness & $\begin{array}{l}\text { "I would like get up a couple of times...I don't want to bother them. } \\
\text { Let me just get up here and go."-Patient, Hospital F }\end{array}$ \\
\hline
\end{tabular}

\subsection{Facilitators to Fall TIPS Adoption}

\subsubsection{Staff were Motivated to Address Falls}

Hospital leadership was credited for instilling a shared vision of fall prevention among staff. Falls became a standing agenda item during daily huddles and staff meetings. Here, nursing leaders communicated: 1 ) the preventable nature of falls; 2) Fall TIPS as a proven fall prevention method; and 3) the need to engage patients in the three-step fall prevention process. Nurses at each health system also received mandatory Fall TIPS trainings that were delivered via online learning modules or hands-on workshops and routinely received falls audit and outcomes data. Audit data depicted staff compliance with each step of Fall TIPS. Outcomes data specified the incidence or rate of falls and falls with injury. Staff noted the sharing of these data fostered ownership and accountability for falls.

Staff were similarly motivated to adopt Fall TIPS because they recognized the limitations of their previous fall prevention programs. The previous fall-risk screening assessment was viewed as non-discriminatory, which led to the overuse and diminished effectiveness of interventions (e.g., bed alarms). Pre-Fall TIPS, staff described that most patients were labelled "high-falls risk" and would receive "high-falls risk" interventions, inclusive of bed alarms and high-falls risk posters. 
Consequently, interventions became ubiquitous and lost their significance, with staff referring to high-falls risk posters as "wallpaper" and bed alarms as "noise."

\subsubsection{Patients and their Families Welcomed their Role in Fall Prevention}

Patients and their families readily understood the need for individualized fall plans and welcomed their role in fall prevention. Patients noted their participation was facilitated by 1 ) nurse-initiated conversations in which fall risk factors and accompanying interventions were discussed and reinforced; and 2) bedside fall-plan posters. Nurse-initiated conversations were said to occur during admission, hourly rounding, and bedside shift report. Patient-initiated conversations were said to result from patient's review of bedside fall-plan posters. Patients expressed a high degree of confidence that they would not fall while in the hospital and patient families similarly noted the falls program instilled a "peace of mind" regarding their loved one's safety.

\subsubsection{Fall TIPS was Integrated into Existing Staff Workflows}

Staff described the ease of using Fall TIPS as it was incorporated into their existing workflows. Fall TIPS was integrated into the electronic medical documentation of participating hospitals. In doing so, fall-risk screenings became part of the electronic documentation of nurses' daily assessment for each patient. Similarly, clinical decision support aided nurses' identification of interventions that targeted individual fall risk factors. Electronic health records pulled fall risk factors and associated interventions into printed bedside fall-plan posters, which ensured the consistency of information and minimized duplicative work. Fall TIPS was also modified to accommodate existing staff workflows. Four hospitals enabled the remote printing of bedside fallplan posters from wireless computers, whereas the remaining two hospitals used laminated Fall TIPS posters to depict a patient's individualized fall plan.

\subsection{Barriers to Fall TIPS Adoption}

\subsubsection{Poor Patient Engagement Practices among Staff}

Poor patient engagement practices were noted to limit the effectiveness of Fall TIPS. These practices included staff instructing patients of their fall prevention plan, rather than partnering with patients in the development and implementation of fall prevention plans, and staff failing to update bedside fall-plan posters with accurate information. Staff provided several reasons for these practices, including perceptions that engaging patients in fall prevention was time consuming, the belief that patient education was the same as patient engagement, and a lack of staff accountability for poor fall prevention practices. To address these barriers, staff recommended ongoing education that emphasizes the importance of patient engagement on fall outcomes, specific guidance on how staff may engage patients in fall prevention, and measures to hold staff accountable in fall prevention (e.g., individualized staff feedback on fall prevention practices). 


\subsubsection{Residual Language and Fall Prevention Approaches}

The continued categorization of patients as "high" and "low" falls-risk and the ensuing implementation of universal "high-falls risk" interventions were noted to perpetuate a one-size fits all approach to fall prevention and conflict with Fall TIPS. High-falls risk interventions (bracelets, generic signs, etc.) were considered inactionable as they failed to communicate specific activities to prevent the occurrence of falls and caused confusion with the patient-tailored focus of Fall TIPS. To address this conflict, staff recommended the elimination of interventions from previous fall prevention programs when inconsistent with Fall TIPS and ongoing education to reinforce Fall TIPS procedures.

\subsubsection{Patient-Level Considerations}

Patient willfulness, defined as patient's conscious deviation from fall prevention plans presented challenges to Fall TIPS program fidelity. Patients and staff described scenarios in which patients were knowledgeable of their fall prevention plan yet did not follow it because they "did not want to bother the nurse," or "could do it on their own." To address this barrier, patients and staff noted the importance of staff behavior in showing that patients are not a bother and the availability of staff to assist. Staff also reported using stories to engage patients in their fall plans, in which staff described the negative outcomes patients sustained as a result of fall prevention plans not being followed. Staff underscored difficulty engaging patients with cognitive impairments and noted the importance of engaging families among this patient group.

\section{Discussion}

We found that the successful adoption of Fall TIPS resulted in a novel partnership between staff and patients to prevent falls and required substantial leadership commitment, the engagement of staff and patients, and workflow integration. To date, patients have primarily been viewed as the passive recipients of inpatient fall prevention interventions. Patient-facing fall prevention interventions have been classified by recent systematic reviews as "patient education" [13] and "patient-level quality improvement strategies (e.g., patient education and patient reminders)" [14]. The Prevention of Falls Network Europe (ProFaNE) network's taxonomy of fall interventions [15], which has guided fall intervention systematic reviews performed by the Cochrane Collaboration and U.S. Preventative Services Task Force (USPSTF) [16, 17], includes "knowledge e.g., written materials, videos, lectures, etc." as a subdomain of intervention descriptors. Yet, strategies to improve uptake/adherence are subsumed within the subdomain, 'further specifications of the intervention' [15]; thus, demonstrating the lack of patient engagement focus in the fall prevention literature. Similarly, while the USPSTF's most recent fall and fracture prevention guideline [18] is noted to be relatively simple for providers to implement (e.g., recommending that patients exercise), the effectiveness of recommendations rely on long-term behavioral changes and action among patients, which has not been adequately addressed [19].

A growing body of evidence has found that patient engagement and more specifically, patient activation, defined as a patient's knowledge, skill, and confidence in managing their health, is associated with improved health outcomes [20,21]. While patient activation has yet to be published in the context of fall prevention, existing literature has shown that patient's knowledge 
of fall prevention interventions does not necessitate patient's adherence to fall prevention interventions. A case-control study to learn why patients fell revealed that patients fell when they did not follow fall interventions [22]. Similarly, in our study, we found that despite patients' ability to articulate their fall risks and accompanying interventions, patients consciously deviated from fall plans because they did not want to bother staff or they overestimated their walking abilities. These findings highlight patients as agents in fall prevention and show the vulnerability that occurs when mismatches exist between the fall-prevention interventions that staff want to implement and those that patients are willing to carry out. Additional research is needed to identify strategies that effectively improve patient engagement in fall prevention. Staff behavior and staff availability, as noted in our study, were noted to play a role in patient's behavior in fall prevention.

The adoption of Fall TIPS also resulted in the first-time use of clinical decision support to identify patient-tailored fall prevention interventions. Fall prevention programs have traditionally relied on staff expertise to develop patients' fall prevention plans [6] despite studies showing that staff have poor mean fall prevention knowledge scores (5.1 \pm 1.8 out of 11) [23], and that staff's selection of fall prevention interventions lacks evidence [24]. In contrast, the interventions articulated in Fall TIPS are based upon the 6-item Morse Fall Scale (MFS) [25]. The MFS contains actionable risk factor items that have been thoroughly tested $[26,27]$ and prospectively evaluated [28]. A recent systematic review of fall prevention approaches found that the majority of fall prevention programs ( 23 of 43 reviewed) used risk assessment scales that had not been validated and, furthermore, among validated scales, the MFS was most commonly used (6 of 43) [13]. Fall TIPS builds upon individual MFS risk factor items by identifying specific interventions that target individual fall risks.

Additional facilitators to Fall TIPS adoption included the ease of use and understandability of Fall TIPS, which are likely due to the participatory-based, end-user design on which Fall TIPS was built. As part of the development of Fall TIPS, patients shared their perspectives about falling while hospitalized; why they fell [29] and their views about preventing falls [30]. Similarly, nurses' and patients' opinions of icons illustrating the risk factors identified by the MFS provided initial validation of poster icons that linked identified risks with evidence informed interventions to ameliorate those risks [31, 32]. Despite end-users' active involvement in Fall TIPS development, we found that patient engagement, a core principle of Fall TIPS remained unclear for some staff, with these staff perceiving patient education to be the same as patient engagement or reporting that they did not know how to engage patients.

We developed the website www.falltips.org in response to study findings. The website contains programmatic details of the facilitators that should be enhanced and barriers that should be overcome to promote the successful adoption of Fall TIPS. The resources and tools made freely available on the website directly address the barriers identified herein, including information for staff that distinguishes patient education from patient engagement and exercises for staff to effectively engage patients in fall prevention.

\subsection{Limitations}

This study has several limitations. Data were collected from stakeholders at three academic health systems with high rates of Fall TIPS compliance who were willing to contribute up to an hour of time. Future studies are needed to explore barriers to Fall TIPS adoption among hospitals 
with lower compliance rates. Similarly, the voluntary self-selection of participants had the potential for including subjects with extremely positive or negative experiences with Fall TIPS. The findings reported herein are also across all study participants and not specific to the geriatric population. However, hospital-based fall prevention programs are most effective if they are used and perceived to be effective with all patients. This study provides important information about barriers and facilitators to the adoption of Fall TIPS that can benefit geriatric as well as younger patients. Three teams of researchers conducted interviews at their respective sites, which could have led to differences in interviewing quality. This potential limitation was overcome by day-long training programs where interviewers demonstrated competency in qualitative interviewing techniques using the different stakeholder guides. The incorrect interpretation of transcript data was prevented by having a second round of interviews at each site in which stakeholders were queried about provisional findings. The greatest strength of this study is our qualitative approach. We obtained rich data in the exact words of stakeholders who had direct experience with Fall TIPS. While quantitative research methods could provide data regarding the effectiveness of Fall TIPS, our goal was to learn how best to spread Fall TIPS to other hospitals.

\section{Conclusions}

Fall TIPS facilitated a paradigm shift in fall prevention by placing an unprecedented focus on patient engagement and clinical decision. An appreciation of the facilitators and barriers to Fall TIPS adoption may assist program spread and the partnership of patients in inpatient fall prevention.

\section{Acknowledgments}

This investigation is part of a mixed-methods study to evaluate Fall TIPS (R18HS025128) funded by the Agency for Healthcare Research Quality (AHRQ).

\section{Additional Materials}

The following additional materials are uploaded at the page of this paper.

1. Supplement A: Patient Interview Guide.

2. Supplement B: Staff Interview Guide.

\section{Author Contributions}

$P D, A H, S R L, D W B, J A, M G$ : study design. $E C, S K, M D, P D, A H$ : qualitative analysis. $E C, S K, M E L$, $L A, M S, A H, M D, A H, K C, S P Y, D C, E J, P D$ : acquisition of subjects and data. All authors: drafting and revision of manuscript. EC takes final responsibility for the paper.

\section{Competing Interests}

The authors have declared that no competing interests exist. 


\section{Disclaimer}

The findings and conclusions in this document are those of the authors, who are responsible for its content, and do not necessarily represent the views of AHRQ. No statement in this report should be construed as an official position of AHRQ or of the U.S. Department of Health and Human Services.

This work was presented as an oral presentation at the 2019 Society General Internal Medicine Annual Meeting, May 8-11, 2019 in Washington DC.

\section{References}

1. Staggs VS, Mion LC, Shorr RI. Consistent differences in medical unit fall rates: Implications for research and practice. J Am Geriatr Soc. 2015; 63: 983-987.

2. Bouldin ELD, Andresen EM, Dunton NE, Simon M, Waters TM, Liu M, et al. Falls among adult patients hospitalized in the United States: Prevalence and trends. J Patient Saf. 2013; 9: 13-17.

3. Wong CA, Recktenwald AJ, Jones ML, Waterman BM, Bollini ML, Dunagan WC. The cost of serious fall-related injuries at three midwestern hospitals. Jt Comm J Qual Patient Saf. 2011; 37: 81-87.

4. Centers for Medicare \& Medicaid Services. Hospital-acquired conditions. Baltimore, MD.: Centers for Medicare \& Medicaid Services.; 2019 [Available from: https://www.cms.gov/medicare/medicare-fee-for-service-payment/hospitalacqcond/hospitalacquired conditions.html.

5. Miake-Lye IM, Hempel S, Ganz DA, Shekelle PG. Inpatient fall prevention programs as a patient safety strategy: A systematic review. Ann Intern Med. 2013; 158: 390-396.

6. Barker AL, Morello RT, Wolfe R, Brand CA, Haines TP, Hill KD, et al. 6-pack programme to decrease fall injuries in acute hospitals: Cluster randomised controlled trial. BMJ. 2016; 352: h6781.

7. Dykes PC, Carroll DL, Hurley A, Lipsitz S, Benoit A, Chang F, et al. Fall prevention in acute care hospitals: A randomized trial. JAMA. 2010; 304: 1912-1918.

8. Dykes PC, Duckworth M, Cunningham S, Dubois S, Driscoll M, Feliciano Z, et al. Pilot testing fall tips (tailoring interventions for patient safety): A patient-centered fall prevention toolkit. Jt Comm J Qual Patient Saf. 2017; 43: 403-413.

9. Collaborative. FT. Fall T.I.P.S. A Patient-Centered Fall Prevention Toolkit 2019. Accessed February 20, 2019.

10. Glasgow RE, Vogt TM, Boles SM. Evaluating the public health impact of health promotion interventions: The RE-AIM framework. Am J Public Health. 1999; 89: 1322-1327.

11. Hsieh HF, Shannon SE. Three approaches to qualitative content analysis. Qual Health Res. 2005; 15: 1277-1288.

12. Birt L, Scott S, Cavers D, Campbell C, Walter F. Member checking: A tool to enhance trustworthiness or merely a nod to validation? Qual Health Res. 2016; 26: 1802-1811.

13. Hempel S, Newberry S, Wang Z, Booth M, Shanman R, Johnsen B, et al. Hospital fall prevention: A systematic review of implementation, components, adherence, and effectiveness. J Am Geriatr Soc. 2013; 61: 483-494. 
14. Tricco AC, Thomas SM, Veroniki AA, Hamid JS, Cogo E, Strifler L, et al. Comparisons of interventions for preventing falls in older adults: A systematic review and meta-analysis. JAMA. 2017; 318: 1687-1699.

15. Lamb SE, Becker C, Gillespie LD, Smith JL, Finnegan S, Potter R, et al. Reporting of complex interventions in clinical trials: Development of a taxonomy to classify and describe fallprevention interventions. Trials. 2011; 12: 125.

16. Guirguis-Blake JM, Michael YL, Perdue LA, Coppola EL, Beil TL, Thompson JH. U.S. Preventive services task force evidence syntheses, formerly systematic evidence reviews. Interventions to prevent falls in community-dwelling older adults: A systematic review for the us preventive services task force. Rockville, MD: Agency for Healthcare Research and Quality (US); 2018.

17. Hopewell S, Adedire O, Copsey BJ, Boniface GJ, Sherrington C, Clemson L, et al. Multifactorial and multiple component interventions for preventing falls in older people living in the community. Cochrane Database Syst Rev. 2018; 7: CD012221.

18. US Preventive Services Task Force. Vitamin D, calcium, or combined supplementation for the primary prevention of fractures in community-dwelling adults: US preventive services task force recommendation statement. JAMA. 2018; 319: 1592-1599.

19. Reuben DB. New prevention guidelines for falls and fractures-looking beyond the letters. JAMA Intern Med. 2018; 178: 892-893.

20. Hibbard JH, Greene J. What the evidence shows about patient activation: Better health outcomes and care experiences; fewer data on costs. Health Aff (Millwood). 2013; 32: 207214.

21. Greene J, Hibbard JH, Sacks R, Overton V, Parrotta CD. When patient activation levels change, health outcomes and costs change, too. Health Aff (Millwood). 2015; 34: 431-437.

22. Dykes PC, EH IC, Soukup JR, Chang F, Lipsitz S. A case control study to improve accuracy of an electronic fall prevention toolkit. AMIA Annu Symp Proc. 2012; 2012: 170-179.

23. Dykes PC, Bogaisky M, Carter EJ, Duckworth M, Hurley AC, Jackson EM, et al. Development and validation of a fall prevention knowledge test. J Am Geriatr Soc. 2019; 67: 133-138.

24. Fehlberg EA, Lucero RJ, Weaver MT, McDaniel AM, Chandler AM, Richey PA, et al. Impact of the cms no-pay policy on hospital-acquired fall prevention related practice patterns. Innov Aging. 2017; 1.

25. Morse JM. The safety of safety research: The case of patient fall research. Can J Nurs Res. 2006; 38: 73-88.

26. Morse JM, Prowse MD, Morrow N, Federspeil G. A retrospective analysis of patient falls. Can J Public Health. 1985; 76: 116-118.

27. Morse JM. Computerized evaluation of a scale to identify the fall-prone patient. Can J Public Health. 1986; 77 Suppl 1: 21-25.

28. Morse JM, Black C, Oberle K, Donahue P. A prospective study to identify the fall-prone patient. Soc Sci Med. 1989; 28: 81-86.

29. Carroll DL, Dykes PC, Hurley AC. Patients' perspectives of falling while in an acute care hospital and suggestions for prevention. Appl Nurs Res. 2010; 23: 238-241.

30. Dykes PC, Carroll DL, Hurley AC, Benoit A, Middleton B. Why do patients in acute care hospitals fall? Can falls be prevented? J Nurs Adm. 2009; 39: 299-304. 
31. Hurley AC, Dykes PC, Carroll DL, Dykes JS, Middleton B. Fall TIP: Validation of icons to communicate fall risk status and tailored interventions to prevent patient falls. Stud Health Technol Inform. 2009; 146: 455-459.

32. Leung WY, Adelman J, Bates DW, Businger A, Dykes JS, Ergai A, et al. Validating fall prevention icons to support patient-centered education. J Patient Saf. 2017. doi: 10.1097/PTS.0000000000000354.

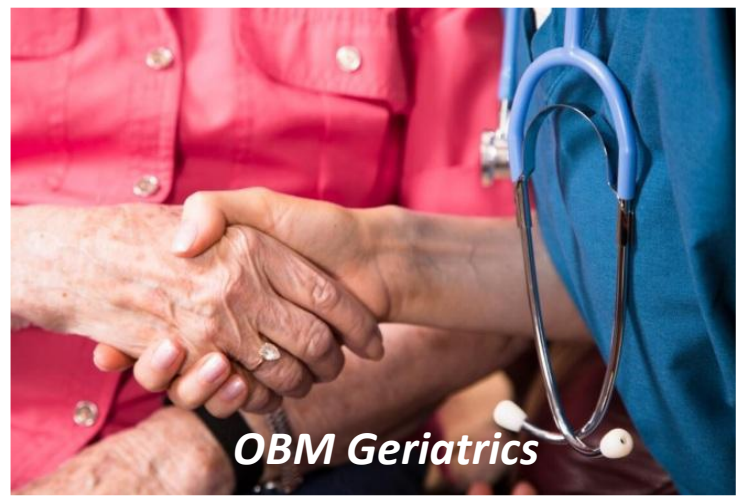

Enjoy OBM Geriatrics by:

1. Submitting a manuscript

2. Joining in volunteer reviewer bank

3. Joining Editorial Board

4. Guest editing a special issue

For more details, please visit:

http://www.lidsen.com/journals/geriatrics 